\title{
Research Paper: Prevalence of Opioid Poisoning and Related Factors in Under 17-year-olds
}

\author{
Mahdi Foroughian ${ }^{1}$ (D, Davood Soroosh ${ }^{2 *}$ (D) \\ 1. Department of Emergency Medicine, Faculty of Medicines, Mashhad University of Medical Science, Mashhad, Iran. \\ 2. Department of Internal Medicine, School of Medicine, Sabzevar University of Medical Sciences, Sabzevar, Iran.
}

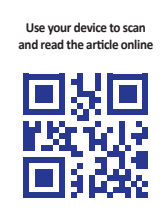

Citation: Foroughian M, Soroosh D. Prevalence of Opioid Poisoning and Related Factors in Under 17-year-olds. International Journal of Medical Toxicology and Forensic Medicine. 2021; 11(2):32392. https://doi.org/10.32598/ijmtfm.v11i2.32392

https://doi.org/10.32598/ijmtfm.v11i2.32392

\section{(i) (3)}

Article info:

Received: 27 Sep 2020

First Revision: 14 Oct 2020

Accepted: 30 May 2021

Published: 23 Jun 2021

\section{Keywords:}

Poisoning, Opioids, Children

\section{A B STRACT}

Background: Poisoning is among the leading causes of childhood injuries. With the increasing prevalence of substance dependence in the community, there is a rise in the frequency of children admitted to hospitals with drug intoxication. Therefore, we investigated the prevalence of acute opioids poisoning in children.

Methods: The present cross-sectional study was performed on children under 17 years of age who were admitted to Sabzevar hospitals with a diagnosis of opioids poisoning. A researchermade checklist was used for data collection, including the patient's age, gender, intoxication agent, drug consumption route and form, hospitalization length and outcome, family's educational level, occupational status, and living area. Besides, descriptive tests were used in SPSS to analyze the obtained data.

Results: In total, 129 cases of opioids poisoning were reported during the study period. The mean \pm SD age of the studied children was $2.74 \pm 3.05$ years. The minimum and maximum ages of poisoned children were 1 and 16 years, respectively. The liquid-soluble form was the most common form of opioids used $(38.3 \%)$. Opium was also the most commonly used substance (68.45\%). In 85 (65.89\%) children, a decrease in Glasgow Coma Scale (GCS) was observed at baseline. Moreover, 7 of the explored children have died. Besides, $90.7 \%$ of their fathers and $95.3 \%$ of their mothers had an educational level of a diploma or below. The most common factor associated with opium poisoning was the family's substance dependence in 120 (93\%) cases. Substance dependence in children was mostly observed in those aged 3-5 years.

Conclusion: Poisoning with opium is the most common type of children's opioid poisoning in Sabzevar. A decreased level of consciousness is the most frequent manifestations in these patients. Therefore, in all children, by observing a sudden decrease in the level of consciousness without apparent reasons, especially along with other symptoms, such as acute diarrhea, restlessness, etc., it is recommended to consider opioids poisoning.

\section{* Corresponding Author:}

Davood Soroosh, MD.

Address: Department of Internal Medicine, School of Medicine, Sabzevar University of Medical Sciences, Sabzevar, Iran.

Tel: +98 (51) 44651300

E-mail:davoodsoroosh@yahoo.com 


\section{Introduction}

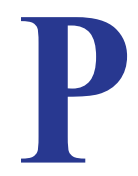

oisoning with opium and its derivatives is a dangerous and fatal poisoning that can lead to decreased consciousness, coma, apnea, respiratory depression, and eventually death. A major cause of death in children is opioids poisoning [1]. The poisoning prevalence varies according to the geographical and cultural features of different communities [2].

Additionally, the poisoning pattern in a country depends on various factors, including socioeconomic and cultural status, access to various toxins, and religious beliefs of the community [3, 4]. A major cause of poisoning in children is the accidental eating of poisonous substances; such poisoning is most prevalent in the age group of 1-5 years [5-7]. In Iranian children, drug and oil poisonings are the most prevalent causes of death due to poisoning, respectively [6]. Using methadone has increased for treating opioids dependence at home. Thus, poisoning with methadone may accidentally occur in children or even adults. It may also be used with the intent to commit suicide or premeditated murder [8]. The literature indicates that several cases of intentional or accidental poisoning of children with methadone and its complications and induced death have been recorded in Iran [1, 9-11]. Masoudpour et al. examined the frequency and factors associated with methadone poisoning in children under 15 years of age referring to the pediatric emergency department of Ali Ibn Abi Taleb Hospital in Rafsanjan. They found that season, family's economic status, place of residence, maternal condition, substance dependence, and the birth order of the child were the most important factors related to methadone poisoning in children [12]. Farzaneh et al. conducted an epidemiological study concerning acute poisoning in children who were referred to Bu Ali Hospital in Ardabil. The relevant results revealed that the most common cause of poisoning among children, as the majority of studies, was drugs; methadone was the most frequent substance in this regard [7]. Recognizing the poisoning patterns in a particular area plays a critical role in identifying risk factors and an early recognizing of poisoning [13]. Moreover, designing strategies to prevent suicide and reduce the risks of accidental poisoning will be easier by understanding the pattern of poisoning [14].

The number of hospitalizations due to opioids poisoning in the educational and medical hospitals of Sabzevar is on the rise; thus, this study investigated the prevalence of opioids poisoning and its related factors in children under 17 years of age in Sabzevar City, Iran, in 2018 and
2019. Besides, this study aimed to reach some appropriate solutions by obtaining demographic, therapeutic, and clinical information and studying related factors.

\section{Materials and Methods}

The present study was a prospective cross-sectional study that was performed on hospitalized children under 17 years of age with a diagnosis of opioid poisoning in hospitals of Sabzevar city during one year from winter 2018 to winter 2019.

Before the inclusion of patients (hospitalized children) in this study, the research process was explained to the children and parents; a written informed consent form was obtained from all study subjects (the parents of hospitalized children). Throughout the study, researchers adhered to the principles of the Helsinki Declaration and the confidentiality of patient information. The researchers supported all costs of the project and no additional costs were incurred by the patients. This study was approved by the Ethics Committee of Sabzevar University of Medical Sciences (code IR.MEDSAB. REC.1397.052).

Children aged under 17 years and diagnosed with opioids poisoning were included in the present study.

Violation in the medical file and parents' dissatisfaction to participate in the study were the exclusion criteria of the study.

The patients' information was collected from December 2018 to March 2019. All children under 17 years of age who were admitted to Sabzevar City hospitals (Vasei \& Heshmatieh hospitals) with a diagnosis of opioids poisoning were examined in this research. Applying the census sampling method, we included 129 children with opioids poisoning. Demographic information, including age, gender, the place of residence, parental occupation, education, and economic status, and other related data (e.g. a history of substance dependence in the child, parents, time interval between consumption and hospitalization, clinical manifestations at admission, the amount of naloxone administered, outcomes, \& the duration of hospital stay) were collected and recorded in the data gathering form. These data were collected through interviews with the parents or companions of the child, the medical examination of the poisoned children, and the information recorded in the files. In cases where the social information was unavailable, the file was completed by a telephone call. 
Table 1. Demographic characteristics of patients

\begin{tabular}{ccccc}
\hline \multirow{2}{*}{ Demographic characteristics } & & Frequency & Relative percentage & Cumulative percentage \\
\cline { 2 - 4 } sex & Male & 71 & 55 & 55 \\
& Female & 58 & 45 & 100 \\
Habitat & Urban & 58 & 45 & 45 \\
& Rural & 71 & 55 & 100 \\
& 1 & 45 & 36.3 & 36.3 \\
Time (days) & 2 & 46 & 37.1 & 73.4 \\
& 3 & 28 & 22.6 & 96 \\
& 4 & 4 & 2.3 & 99.2 \\
\end{tabular}

Mean and standard deviation were used to describe quantitative variables; percentages and frequency were employed to describe qualitative variables. The Chisquared or Fisher's Exact tests were used to analyze the collected data in SPSS.

\section{Results}

A total of 5347 children under the age of 17 years who were poisoned with opioids during the study period were studied. Of them, 187 cases were hospitalized due to acute poisoning. The opioids poisoning prevalence was measured as $68.98 \%$ in pediatric poisoning cases $(\mathrm{N}=129)$. The mean $\pm \mathrm{SD}$ age of the explored patients was $2.74 \pm 3.05$ years. The minimum and maximum ages of the studied children referring to Sabzevar hospitals with opioids poisoning were 1 and 16 years, respectively. Opioids poisoning was more observed in male children $(55 \%)$. The mean \pm SD hospital stay was equal to $1.95 \pm 0.089$ days (Table 1). Despite the treatment, 7 (5\%) children died during the study period. In total, 71 (55\%) and $58(45 \%)$ cases of opioids-poisoned patients were living in rural and urban areas, respectively.

Additionally, the most frequent symptoms in urban and rural resident patients were the loss of consciousness (41.5\% \& 58\%, respectively). The seizure was also the least common symptom. Only one child living in a rural area experienced a seizure at the time of admission to the hospital.

Decreased Glasgow Coma Scale (GCS) was present in 85 children with opioids poisoning at admission; it was the only symptom in $41.8 \%$ of the study patients. GCS was the most common symptom by gender $(37.7 \%$ \& $30.2 \%$ in males \& females, respectively). Furthermore, the frequency of GCS decline in these patients at different ages varied from $28.6 \%$ to $100 \%$; most of which was at the beginning of school years (6-7-year-olds) (Table 2). Besides, 11(9\%) children with opium poisoning presented restlessness; 5 of which were associated with decreased GCS. During this study, one of the hospitalized children with opioids poisoning was in a coma at admission.

Furthermore, $117(90.7 \%)$ of the fathers and $95.3 \%$ of the mothers had a high school diploma or below. The highest rates of opium poisoning were detected in the children whose fathers had a freelance-based profession (58 cases; $45 \%$ ) or farmers $(41.8 \%)$. Also, in 117 $(90.7 \%)$ cases, their mothers were housewives (Table 3 ).

In 120 (93\%) cases, a family's substance dependence was the most common factor associated with opium poisoning in children. Substance dependence was also observed in $26(20.2 \%)$ cases of the poisoned children. Concerning gender, children's substance dependence was similar to some extent $(21.1 \%$ in males \& $19 \%$ in females). In this study, the highest age of individuals with substance dependence belonged to those aged 3-5 years (about 25\%) (Table 3).

The most common form of opioids use in children was the liquid-soluble type in $49(38.3 \%)$ cases, followed by the inhaled form in $40(31.2 \%)$ subjects. The most commonly used substances were opium and methadone in $81(63.3 \%)$ and $29(22.7 \%)$ individuals, respectively (Table 4). 
Table2. Frequency of symptoms in children with opioid poisoning

\begin{tabular}{ccc}
\hline Symptoms & Frequency & Relative percentage \\
\hline Decrease GCS & 51 & 41.8 \\
\hline Agitation & 5 & 4.1 \\
\hline Miosis, Decrease GCS & 27 & 22.2 \\
\hline Agitation, Decrease GCS & 5 & 4.1 \\
\hline Seizure, Miosis, Decrease GCS & 2 & 1.6 \\
\hline Agitation, Miosis & 1 & 0.8 \\
Coma & 1 & 0.8 \\
\hline others & 37 & 24.6 \\
\hline Total & 129 & 100 \\
\hline
\end{tabular}

\section{Discussion}

In the present study, the frequency of opioids poisoning was calculated as $129(68.45 \%)$ cases of the total 187 cases of acute poisoning, i.e., admitted among 5347 children referred to Sabzevar hospitals. Mojtabaei et al. also found that out of 3299 children admitted to the emergency department of 17 Shahrivar Hospital in Rasht, 141 encountered poisoning with drugs, oil, detergents, opium, rat poison, poisonous plants, insecticides, and snake bites [15]. Masoudpour et al. examined the frequency and factors related to methadone poisoning in children under 15 years of age referring to the pediatric emergency department of Ali Ibn Abi Taleb Hospital in Rafsanjan. They found that 97 children were hospitalized with methadone poisoning [12]. Amani et al. reported the prevalence of opioid poisoning as $24.1 \%$ (81 out of 336 poisoning cases) [16]. The present study results are almost in line with those of Mojtabaei et al. [15], Amani et al. [16], and Masoudpour and associates [12].

Farzaneh studied the epidemiology of acute poisoning in children who were referred to Bu Ali Hospital in Ardabil from 2007 to 2011. They concluded that 336 children under the age of 13 years were hospitalized in these 5 years [7].

Cheraghali et al. argued that out of 563 patients referring to the poisoning ward, 305 reported drug poisoning. The results also signified that more than half of these cases were opioids poisoning [17]. Elahimehr et al. explored the causes of poisoning in children referring to Bahonar Hospital in Karaj for one year. The related re- sults demonstrated that 309 children under 14 years of age were exposed to drug and opium poisoning during this one year [18]. Farnaghi et al. also documented that 31 male and female children with methadone poisoning were admitted to Loghman-Hakim Hospital [1]. However, the present study data are inconsistent with those of Farzaneh et al. [7], Cheraghali et al. [17], Elahimehr et al. [18], and Farnaghi and colleagues [1].

The reason for such data inconsistency is the climatic and ethnic demographic conditions of the studies and the studied years respecting the poisoning rate.

The prevalence of opioids poisoning in $71(55 \%)$ male children was higher than that in their female counterparts with 58 cases $(45 \%)$. The obtained data are in line with the studies conducted by Elahimehr et al. [18], Haresabadi et al. [19], Masoudpour et al. [12], Farnaghi et al. [1], Oguche et al. [20], Kashani et al. [21], Sharif et al. [22], Manouchehrifar et al. [23], and Farzaneh and associates [7]. Various studies in other countries also reported that the number of poisoned male children was more than the number of female children [24-28].

However, in the studies conducted by Zamani et al. [29] and Atighi et al. [30], the female cases of poisoning were higher than that in males, i.e., inconsistent with the present study findings.

In this study, the highest prevalence of poisoning belonged to children under one year of age with 71 (55\%) cases. However, in the studies conducted by Haresabadi et al. [19], Miri [31] in Ardabil; Kashef and Hani [32] in Yazd; Qureishi et al. [33] in Tabriz, Mojtabaei in Rasht 
Table 3. Frequency of poisoning-related factors in children referred for opioid poisoning

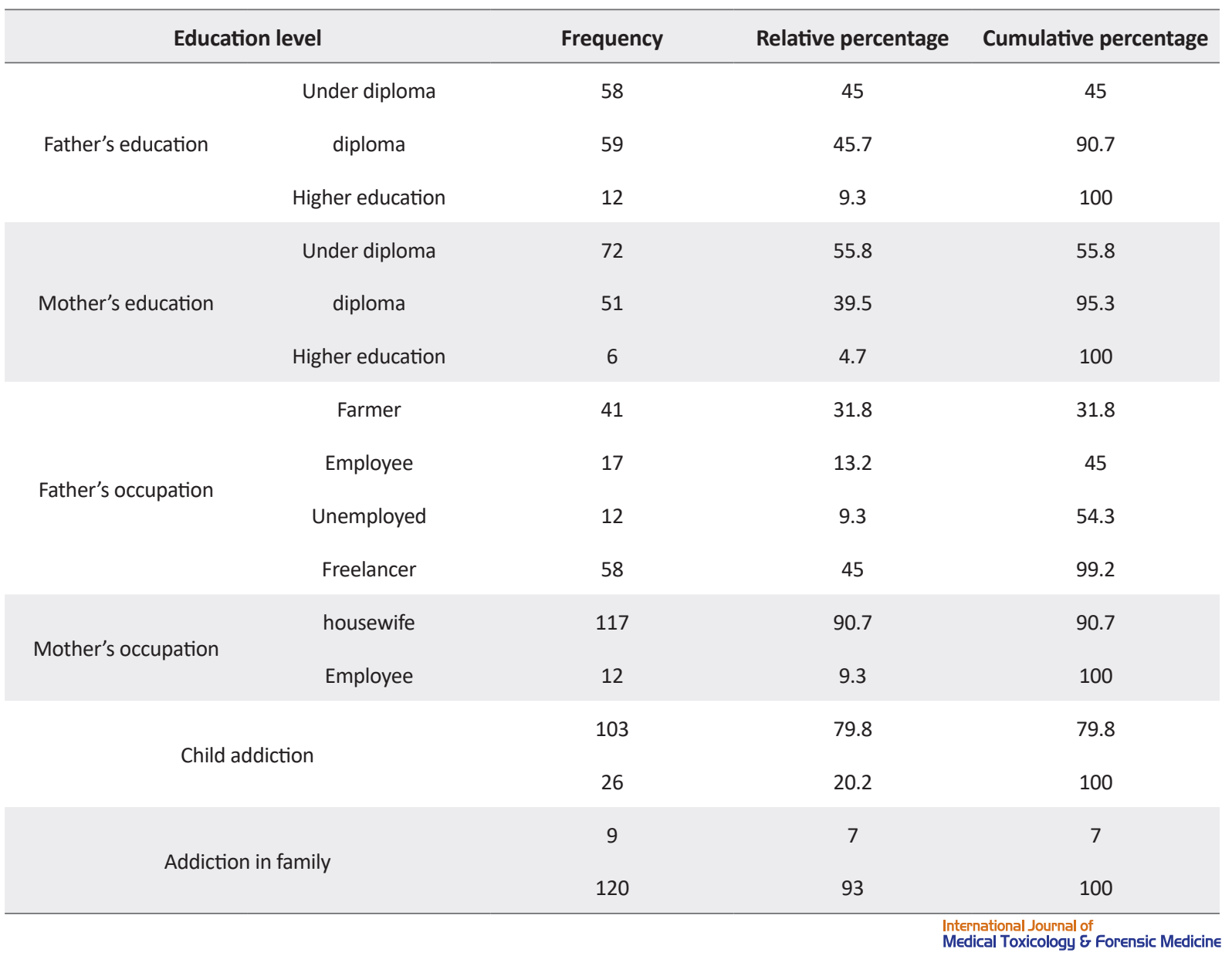

[15], the highest prevalence of poisoning was observed in the age groups of $<6$ months, 1-4 years, 1-5 years, 1-3 years, $1-5$ years, and 1-3 years, respectively. It seems that most cases of poisoning occur in the age group of 1-3 years. In the present study, the most common types of poisoning were related to opium and methadone, respectively. Studies highlighted the growing prevalence of poisoning among children, i.e., among the significant problems in the Iranian healthcare system, like other parts of the world [21]. As per other studies, the prevalence of various types of poisoning is increasing among children [32]. Haresabadi et al. found that the most common cause of poisoning in children was substance use. Additionally, after substance poisoning, medicinal drug poisoning was the most frequent type of poisoning in children [19]. Other studies reflected that half of all poisonings and $91 \%$ of child deaths in some parts of Iran are due to drug poisoning [33]. Methadone is a synthetic and long-acting opioid that, unfortunately, in recent years, emergency room visits due to methadone poisoning and related deaths are on the rise worldwide [1]. In recent years, methadone syrup has replaced methadone tablets in medical centers, and this syrup is colorless; thus, there is a possibility of misuse as water or some other drugs. Therefore, it should be kept out of reach of children to prevent accidental poisoning in them [34-37].

Elahimehr et al. suggested that medicinal drugs (48.5\%) and narcotics $(23.9 \%)$ are the most common causes of poisoning [18]. Gholami et al. reported that the most prevalent type of poisoning is methadone poisoning with a frequency of $70 \%$ [38]. In various studies in Ankara, Hong Kong, China, Romania, and the United States, medicinal drugs were reported as the most frequent cause of poisoning [39-42]. Mansouri found that the most common type of poisoning belongs to narcotics (58.6\%) and medicinal drugs (30\%), respectively [16]. Haresabadi et al. reported that according to the frequency distribution of the acute poisonings in children referring to Imam Reza Hospital in Bojnourd, most of the poisonings were due to narcotics (134 cases; 63.5\%) and medicinal drugs (32 cases; 15.2\%), respectively [19]. Mojtabaei et al. reported that the most common causes of poisoning were drugs and kerosene oil, respectively [15]. Farzaneh et al. 
Table 4. Frequency of types and forms of opioid use in children with opioid poisoning

\begin{tabular}{|c|c|c|c|c|}
\hline \multicolumn{2}{|c|}{ Types and forms } & Frequency & \multirow{2}{*}{$\begin{array}{c}\text { Relative percentage } \\
6.2\end{array}$} & \multirow{2}{*}{$\begin{array}{c}\text { Cumulative percentage } \\
6.2\end{array}$} \\
\hline \multirow{6}{*}{ Route of poisoning } & capsule & 8 & & \\
\hline & syrup & 29 & 22.7 & 28.9 \\
\hline & inhalation & 40 & 31.2 & 60.2 \\
\hline & Dissolved in liquids & 49 & 38.3 & 98.4 \\
\hline & mixed & 2 & 1.6 & 100 \\
\hline & Total & 129 & 100 & \\
\hline \multirow{6}{*}{ Opioid type } & Methadone & 29 & 22.6 & 22.6 \\
\hline & $\begin{array}{l}\text { Opium (except opium } \\
\text { juice) }\end{array}$ & 81 & 63.3 & 85.9 \\
\hline & Opium juice & 13 & 10.2 & 96.1 \\
\hline & Tramadol & 4 & 3.1 & 99.2 \\
\hline & mixed & 1 & 0.8 & 100 \\
\hline & Total & 129 & 100 & \\
\hline
\end{tabular}

also suggested that the most prevalent types of poisoning were drug and kerosene oil poisoning, respectively [7]. In Hong Kong, Hoon et al. reported that drugs, such as acetaminophen, cold medicine, and home remedies were the most common cause of poisoning [40]. According to Arjmand Shabestari et al., drug-poisoning was the most common type of poisoning [36].

Increased methadone use, and the failure to take the necessary measures to prevent poisoning with this dangerous substance in society, have made this substance a threat to children. The higher prevalence of drug poisoning in children can be attributed to the higher curiosity of children and the lack of adequate parental care in the storage of drugs. It can also be explained that the lack of care of parents and other family members has led to using hazardous substances and childhood poisoning. Therefore, the proper storage of this dangerous substance out of the reach of children (placing it in separate boxes in a safe environment or out of reach of children with warning labels) should be taught to parents to reduce the number of such poisonings.

In the present study, the maximum days of hospital stay of patients were 2 and 1 days with a frequency of 46 (37.1\%) and $45(36.3 \%)$ cases, respectively. The average length of hospital stay was 1.95 days. The difference in the treatment period in the mentioned studies may belong to the longer substance dependence history of the subjects that may affect the average day of hospitalization.

In total, 7 (5\%) children died during the study period despite receiving treatment. The mortality rate from poisoning equals $1 \%$ in developed countries and $3 \%$ to $5 \%$ in developing countries. The same rates in Finland, Taiwan, and Nepal are reported as $0.5 \%, 5.7 \%$, and $12 \%$, respectively [35]. In Iran, the mortality rate in Bojnourd was measured as $0.5 \%$ ( 1 case) [19]. Besides, in studies conducted by Farzaneh et al. [7], Besharat et al. [11], as well as Zare Fazl Elahi and Maleki [43], the same rates were $0.59 \%$ ( 2 cases), $6 \%$ (4 cases), and $2.9 \%$, respectively.

Applying some approaches, such as a bitter taste of medicines; using special protective utensils and cases; using recognizable labels for children, and training parents can be useful to prevent drug poisoning and decline the associated child mortality [43]. In the present study, the frequency of opioid poisoning in children in rural and urban areas was $71(55 \%)$ and $58(45 \%)$ cases, respectively. Haresabadi et al. found that the frequency of poisonings in the rural population with $120(56.9 \%)$ cases was more than that in the urban population [19].

Informing families about how to store and use drugs and improving the level of education of parents seem to be effective in reducing children's poisoning in Sabzevar, 
i.e., an important factor in children's health. The present study data revealed that $50 \%$ of children who were dependent on substances had parents with an income of fewer than 1 million tomans per month; no substance dependence was reported in any of the children having parents with an income of more than 3 million tomans.

In line with the present study, Masoudpour et al. concluded that, respectively, 54.6\% (53 cases), 30.9\%, and $14.4 \%$ of the poisoned children had a family with a low, moderate, and high economic status (based on the general opinion of their companions) [12]. Bagheri et al. found that the majority of individuals had an unfavorable economic status [44]. Families with a high economic status seem to bring their poisoned children to the emergency room quickly. As a result, serious and fatal signs and threats on the central nervous system can be prevented. There also exist severe complications of opioids poisoning in some specific opioid agents, like tramadol [45].

Conducting a cohort study to follow the general and psychosocial status of children after discharge and informing physicians and specialists about the statistics and results of the relevant studies can assist other specialists to conduct further practical studies.

\section{Conclusion}

Opioids poisoning is the most frequent type of child poisoning in Sabzevar. The symptoms of decreased level of consciousness are common in these patients; such poisoning is fatal in children. Therefore, in all children, by observing a sudden decrease in the level of consciousness without apparent reasons, especially along with other symptoms, such as acute diarrhea, restlessness, etc., it is recommended to consider opioids poisoning.

\section{Ethical Considerations}

\section{Compliance with ethical guidelines}

This study was approved by the Ethics Committee of Sabzevar University of Medical Sciences (code IR.MEDSAB.REC.1397.052).

\section{Funding}

These study extracted from thesis number 99521802 which financially supported by Sabzevar university of Medical Sciences.

\section{Author's contributions}

All authors equally contributed to preparing this article.

\section{Conflict of interest}

The authors declared no conflicts of interest.

\section{Acknowledgements}

The researchers thank all the staff of Heshmatieh and Vasei hospitals in Sabzevar, especially the emergency department, the poison ward, and the pediatric ward for participating in the present project.

\section{References}

[1] Farnaghi F, Jafari N, Mehregan FF. [Methadone poisoning among children referred to Loghman-Hakim hospital in 2009 (Persian)]. Pajoohande. 2012; 16(6):299-303. http:// pajoohande.sbmu.ac.ir/article-1-1233-en.html

[2] Al-Jahdali H, Al-Johani A, Al-Hakawi A, Arabi Y, Ahmed QA, Altowirky J, et al. Pattern and risk factors for intentional drug overdose in Saudi Arabia. Can J Psychiatry. 2004; 49(5):331-4. [DOI:10.1177/070674370404900509] [PMID]

[3] Jalali A, Savari M, Dehdardargahi S, Azarpanah A. The pattern of poisoning in southwestern region of Iran: Envenoming as the major cause. Jundishapur J Nat Pharm Prod. 2012; 7(3):100-5. [DOI:10.5812/jinpp.3504] [PMID] [PMCID]

[4] Maharani B, Vijayakumari N. Profile of poisoning cases in a Tertiary care hospital, Tamil Nadu, India. J App Pharm Sci. 2013; 3(1):91-4. [DOI:10.7324/JAPS.2013.30117]

[5] Shadnia SH, Esmaily H, Sasanian GH, Pajoumand A, Hassanian-Moghaddam $\mathrm{H}$, Abdollahi M. Pattern of acute poisoning in Tehran-Iran in 2003. Hum Exp Toxicol. 2007; 26(9):7536. [DOI:10.1177/0960327107083017] [PMID]

[6] Hoffman RS, Nelson LS, Howland MA, Lewin NA, Flomenbaum NE, Goldfrank LR. Goldfrank's manual of toxicologic emergencies. 9th ed. New York: McGrow-Hill Professional, 2007. https://books.google.com/books/ about/Goldfrank_s_Manual_of_Toxicologic_Emerge. html?id=Ej3Tty0C2lEC

[7] Farzaneh E, Amani F, Sadeghiyeh S, Sayad Rezaei E, Mirzarahimi M, Mostafazadeh B, et al. [Acute poisoning in adults admitted in Ardabil Imam Khomeini hospital (Persian)]. J Ardabil Univ Med Sci. 2012; 12(5):95-102. http:/ / jarums.arums. ac.ir/article-1-103-en.html

[8] Taheri F, Yaraghi A, Sabzghabaee AM, Moudi M, EizadiMood N, Gheshlaghi F, et al. Methadone toxicity in a poisoning referral center. J Res Pharm Pract. 2013; 2(3):130-4 [DOI:10.4103/2279-042X.122387] [PMID] [PMCID]

[9] Bazmamoun H, Fayyazi A, Khajeh A, Sabzehei MK, Khezrian F. A study of methadone-poisoned children referred to Hamadan's Besat Hospital/Iran. Iran J Child Neurol. 2014 8(2):34-7. [PMID] [PMCID] 
[10] .Jabbehdari S, Farnaghi F, Shariatmadari SF, Jafari N, Mehregan FF, Karimzadeh P. Accidental children poisoning with methadone: An Iranian pediatric sectional study. Iran J Child Neurol. 2013; 7(4):32-4. [DOI:10.22037/ijcn.v7i4.4773] [PMID] [PMCID]

[11] Besharat S, Besharat M, Akhavan-Masuleh A, Jabbari A, Yazdi HR. [Opium intoxication in children under 5 years old, Golestan- Iran (2006-07) (Persian)]. J Gorgan Uni Med Sci. 2010; 12(1): 85-9. http://goums.ac.ir/journal/article1-673-en.html

[12] Masoudpour N, Zare-Bidaki M, Sedighi E, Bakhtar M. [Frequency and related factors of methadone poisoning in children aged under 15 years attending children emergency center of Rafsanjan Ali-Ebne-Abitaleb hospital in 2013 (Persian)]. J Rafsanjan Univ Med Sci. 2015; 14 (7):561-74. http:// journal.rums.ac.ir/article-1-2374-fa.html

[13] Abd-Elhaleem ZAE, Al Muqhem BA. Pattern of acute poisoning in al Majmaah region, Saudi Arabia. Am J Clin Exp Immunol. 2014; 2(4):79-85. http://www.sciencepublishinggroup.com/journal $/$ paperinfo.aspx?journalid $=254 \&$ doi $=10$. 11648/j.ajcem.20140204.15

[14] Bateman DN. The epidemiology of poisoning. Medicine. 2007; 35(10):537-9. [DOI:10.1016/j.mpmed.2007.07.005]

[15] Mojtabaei SM, Bidar N. [Poisoning in children admitted to the emergency ward of Rasht 17 Shahrivar Hospital: A brief report (Persian)]. Tehran Univ Med J. 2012; 70(1):64-7. http:// tumj.tums.ac.ir/article-1-159-en.html

[16] Farzaneh E, Amani F, Mirzarahimi M, Nasrollahtabar M, Sayad Rezaei I. [Epidemiological study of acute poisoning in children referred to Bu-Ali Hospital of Ardabil, 2007-2011 (Persian)]. J Ardabil Univ Med Sci. 2014; 14(1): 55-62. http:/ / jarums.arums.ac.ir/article-1-256-en.html

[17] Cheraghali F, Taymori M. Epidemiological study of drug intoxication in children. Acta Med Iran. 2006; 44(1):37-40. https://acta.tums.ac.ir/index.php/acta/article/view/3135

[18] Elahimehr N, Tavakoli-far B, Bayat G, Sadri H, Arjmand R, Fatemi abhari SM. [Prevalence of acute intoxication in children visiting Shahid Bahonar Hospital in Karaj, Iran, 2014-2015 (Persian)]. Alborz Univ Med J. 2020; 9(2):209-18. [DOI:10.29252/aums.9.2.209]

[19] Haresabadi M, Sedaghat M, Vejdani MA, Ahrari S, Toghian CHaharsougi N, Momeni A. [Epidemiologic study of acute poisoning in children aged under 12 years referred to Imam Reza hospital, 2010-2012 (Persian)]. J North Khorasan Univ Med Sci. 2013; 5(1):47-52. [DOI:10.29252/jnkums.5.1.47]

[20] Oguche S, Bukbuk DN, Watila IM. Pattern of hospital admissions of children with poisoning in the Sudano-Sahelian North Eastern Nigeria. Niger J Clin Pract. 2007; 10(2):111-5. [PMID]

[21] Kashani P, Safari S, Hatamabadi H, Arhami Dolatabadi A, Manouchehrifar M, Dokht Tabrizi M. Characteristics of methadone intoxicated children presenting to emergency department; A Cross Sectional Study. Emerg (Tehran). 2017; 5(1):e80. [DOI:10.22037/emergency.v5i1.18780] [PMID] [PMCID]

[22] Sharif MR, Nouri S. Clinical Signs and symptoms and laboratory findings of methadone poisoning in children. Iran J Pediatr. 2015; 25(1):e176. [DOI:10.5812/ijp.176]
[23] Manouchehrifar M, Derakhshandeh N, Shojaee M, Sabzghabaei A, Farnaghi F. An epidemiologic study of pediatric poisoning; A six-month cross-sectional study. Emerg (Tehran). 2016; 4(1):21-4. [PMID] [PMCID]

[24] Song L, Yin NG, Tian WJ, Gu R, Jia YT. [Clinical features of acute poisoning in hospitalized children: An analysis of 586 cases (Chinese)]. Zhongguo Dang Dai Er Ke Za Zhi. 2017; 19(4):441-5. [DOI:10.7499/j.issn.1008-8830.2017.04.016] [PMID] [PMCID]

[25] Hassan BA, Siam MG. Patterns of acute poisoning in childhood in Zagazig, Egypt: An epidemiological study. Int Sch Res Notices. 2014; 2014:245279. [DOI:10.1155/2014/245279] [PMID] [PMCID]

[26] Kohli U, Kuttiat VS, Lodha R, Kabra SK. Profile of childhood poisoning at a tertiary care centre in North India. Indian J Pediatr. 2008; 75(8):791-4. [DOI:10.1007/s12098-008-0105-7] [PMID]

[27] Rodrigues Mendonca D, Menezes MS, Matos MA, Rebouças DS, Filho JN, de Assis RS, et al. Acute poisoning in children in Bahia, Brazil. Glob Pediatr Health. 2016; 3:2333794x15623243. [DOI:10.1177/2333794X15623243] [PMID] [PMCID]

[28] Lin YR, Wu TK, Liu TA, Chou CC, Wu HP. Poison exposure and outcome of children admitted to a pediatric emergency department. World J Pediatr. 2011; 7(2):143-9. [DOI:10.1007/ s12519-011-0267-7] [PMID]

[29] Zamani N, Sanaei-Zadeh H, Mostafazadeh B. Hallmarks of opium poisoning in infants and toddlers. Trop Doct. 2010; 40(4):220-2. [DOI:10.1258/td.2010.100134] [PMID]

[30] Atighi Y, Eizadi-Mood N, Mansourian M, Zamani A, Saffaei A, Sabzghabaee AM. Predictive factors of treatment outcomes for hospital care in children with acute methadone poisoning. J Res Pharm Pract. 2018; 7(4):200-4. [DOI:10.4103/ jrpp.JRPP_16_141] [PMID] [PMCID]

[31] Tabar Miri F. [Epidemiology of acute poisoning in children Sina hospital from April 2008 to the end of 2011, in Ardebil (Persian)]. [PhD Thesis] Ardabil: University of Medical Sciences; 2011.

[32] .Kashef S, Hani H. One year of acute poisoning in children admitted to emergency wards of Namazi hospital. JSSU. 2018; 10(2):42-6. https://www.sid.ir/fa/journal/ViewPaper. aspx?ID=32434

[33] Qureshi Z, Soltani Ahari H. Acute toxicity studies in Tabriz Pediatric Patients. Ardabil University of Medical Sciences and Health Services 2003; 3(9):59-63. https:/ / scholar.google.com/ scholar?hl=fa\&as_sdt $=0 \% 2 \mathrm{C} 5 \& \mathrm{q}=$ Acute+toxicity + studies + in + Tabriz+Pediatric+Patients\&btnG $=$

[34] Budhathoki S, Poudel P, Shah D, Bhatta NK, Dutta AK, Shah GS, et al .Clinical profile and outcome of children presenting with poisoning or intoxication: A hospital based study. Nepal Med Coll J. 2009; 11(3):170-5. [PMID]

[35] Bentur Y, Obchinikov ND, Cahana A, Kovler N, BloomKrasik A, Lavon O, et al. Pediatric poisonings in Israel: National poison center data. Isr Med Assoc J. 2010; 12(9):554-9. [PMID]

[36] Arjmand Shabestari A, Purfarzad Z, Ghorbani M. Acute Poisoning in Children: A Hospital-Based Study in Arak, Iran (2008-2012). Iranian J Toxicol 2014; 8(26):1104-8. http://ijt. arakmu.ac.ir/article-1-343-en.html 
[37] Shadnia S, Rahimi M, Hassanian-Moghaddam H, Soltaninejad K, Noroozi A. Methadone toxicity: Comparing tablet and syrup formulations during a decade in an academic poison center of Iran. Clin Toxicol (Phila). 2013; 51(8):777-82. [DO I:10.3109/15563650.2013.830732] [PMID]

[38] Gholami N, Alwasabi F, Farnaghi F. Drug-Induced apnea in children admitted to Loghman Hakim hospital, Tehran, Iran. Iran J Child Neurol. 2017; 11(3):15-8. [PMID] [PMCID]

[39] Andiran N, Sarikayalar F. Pattern of acute poisonings in childhood in Ankara: What has changed in twenty years? Turkish J pediatr. 2004; 46(2):147-52. [PMID]

[40] Hon KLE, Ho JKY, Leung TF, Wong Y, Nelson EAS, Fok TF. Review of children hospitalised for ingestion and poisoning at a tertiary centre. Ann Acad Med Singap. 2005; 34(5):356-61. [PMID]

[41] Azab SMS, Hirshon JM, Hayes BD, El-Setouhy M, Smith GS, Sakr ML, et al. Epidemiology of acute poisoning in children presenting to the poisoning treatment center at Ain Shams University in Cairo, Egypt, 2009-2013. Clin Toxicol (Phila). 2016; 54(1):20-6. [DOI:10.3109/15563650.2015.111201 4] [PMID] [PMCID]

[42] Oprescu F, Peek-Asa C, Wallis A, Young T, Nour D, Cherecheş RM. Pediatric poisonings and risk markers for hospital admission in a major emergency department in Romania. Matern Child Health J. 2012; 16(2):495-500. [DOI:10.1007/ s10995-011-0742-8] [PMID] [PMCID]

[43] Zare Fazl Elahi Z, Maleki M. Epidemiological study of poisoning in children admitted to Imam Khomeini Hospital in Urmia, 2002-2006. Scientific Journal of Forensic Medicine. 2009; 15 (3): 171-175.

[44] Bagheri F. [Factors leading to methadone poisoning in children admitted to hospital in Afzalipour (Persian)]. [PhD Thesis] Kerman: Kerman University of Medical Sciences; 2013.

[45] Soroosh D, Foroughian M, Zarmehri B. Investigating the Characteristics of Tramadol-induced Seizures: A Crosssectional Study. IJMTFM. 2020; 10(2):27869-. [DOI:10.32598/ ijmtfm.v10i2.27869] 